\title{
Reply to "No time like the present: time to rethink our habits in science and continuous medical education?"
}

\author{
Stefano Fanti ${ }^{1}$
}

Published online: 25 April 2020

(C) Springer-Verlag GmbH Germany, part of Springer Nature 2020

I read with interest the Editorial written by Frederik Verburg published in the current issue of EJNM [1]. Indeed, I agree with several considerations, first of all regarding the unexpected and dramatic consequences of the current Covid-19 pandemic.

However, there are many points that should be carefully considered, especially by my perspective, being a motivated Medical Congress attendee as well as current EANM Congress Chair. First of all, it is not true that at conferences most attendees are passively sit in continuous medical education sessions: nowadays most sessions are allowing a good interaction, and thus the choice of being proactive is in the hand of participants. Also, it is not correct that speakers are talking more or less intelligibly on a stage in the far distance; in my experience the audio quality at every congress centre is far better that quality of streaming webinar audio, and we frequently see empty seats at front row, thus the distance can be easily reduced.

A truly relevant difference between virtual vs in-person conferences is the quality of communications [2]; several studies and research on deliberative methods have demonstrated that learning and collaboration are facilitated during two-way exchanges [3]. Although a speech or a presentation can be viewed by an unlimited number of the people, streaming video only facilitate one-way communication. For multiway communication to occur, online meetings should allow attendees to interact and ask questions; however, web conferencing can only accommodate a limited number of people, and at present tens or hundreds of attendees cannot interact together effectively [2].

This article is part of the Topical Collection on Editorial

Stefano Fanti

Stefano.fanti@aosp.bo.it

1 Department of Nuclear Medicine, Policlinico S.Orsola, University of Bologna, PAD 30, Policlinico S.Orsola, Bologna, Italy
As Fred Verburg state, it is common experience that sometimes at conferences there are presentations of not great quality, but the problem is clearly not related to the event location or platform, but solely to the presenters. The only strategy to improve the quality of presentation is carefully selecting the speakers and interact with them to promote maximum efforts to provide a great talk, that is exactly what a Congress Chair is expected to do, either in a physical or virtual conference. And the presence of few attendees (proverbially or literally, three people) is not related to the type of event, but only to the interest raised by the session and talk. Going virtual, it is unlikely to magically make all speakers of outstanding quality; and the number of attendees could probably be increased simply because some guys may connect and then doing other stuff, while leaving the streaming running not listened.

I fully agree that 2-3 days jetting across the globe for a presentation is much questionable by an ecological point of view [1]. However, it fully remains in the hand of our personal choice to accept invitation for a talk or declining it: if a colleague that I invite as Congress Chair to Vienna from Australia would not come for the benefit of the reduction of travel pollution, I can surely understand, and eventually find an alternative speaker from a nearby area. Furthermore, international virtual meetings would depend on attendees in different time zones gathering online. A single time cannot oblige every time zone, and organizers are sure to lose those who live in regions where the online meeting occurs at inconvenient times [2].

It is not my opinion that the advantage of a physical congress is about being at a secluded location, without the distractions of everyday life [1]: most events are planned in big cities, and time to dedicate to any activity (including overworking and distractions) is under the control of free will. Also, I cannot agree with Frederick description of a typical congress as "rushing from one appointment to another, from one session to the next, arriving back home stressed" as it is, again, all about individual choices; rather than stay home, you should consider taking less appointments, give less lectures and be more selective for the sessions to attend. 
Online meetings also tend to attract attendees who are already interested or working in the same field or on a similar project. Physically gathering people together encourages people to attend talks and other sessions that may seem to be outside an individual's field or interests [2]. Multidisciplinary and cross-sectoral attendance at talks allows for the exchange of ideas and techniques across fields: therefore, conventional Conferences provide the means for exchange across disciplines and sectors.

In my opinion, there are still many reasons that makes inperson Congress an event worth being attended, and several are mentioned by Fred Verburg: the opportunity for young physicians to meet established scientists; the possibility for established scientists to network with and possibly recruit young talent; the unique chance to socialise outside of the meeting room, and resolving professional differences [1]. All these opportunities are frequently referred as "networking" but such word is very reductive: best targeted network can probably be done via web, for example, via Twitter you can easily reach thousand followers without moving from home; nonetheless we are to every extent very social animals, preferring real smiles over emoticons, and the "human inperson networking" is the true added value of a conventional Congress.

It might be that one day IT and AI will overcome the need of physical meetings, but at present I still feel the need of human interaction, in order to get the best of professional relationship: my favourite and most fruitful discussion about science have occurred at a restaurant table with Uwe Haberkorn and not at a web conference. I am surely stupid and old style, but the pleasure of attending a party with residents and colleagues from five continents fully compensate the rush for meetings and sessions, and motivate me to come back the next year. Of course, those considerations are true for a Congress with an excellent balance of high scientific content and great mood, and this is exactly what we are aimed at keeping high at EANM: the momentum, namely the possibility to enjoy the entire event, by any point of view.

In conclusion, I agree with Frederik that "there is no time like the present" to think about our habits; after weeks of lockdown, we will be even more motivated to attend EANM 2020, and will be my personal due to make it worth the effort of professional travelling.

\section{Compliance with ethical standards}

Conflict of interest The author declares that he has no conflict of interest.

\section{References}

1. Verburg FA. No time like the present: time to re-think our habits in science and continuous medical education? Eur J Nucl Med Mol Imaging. 2020; in press.

2. Oester S, Cigliano JA, Hind-Ozan EJ, Parsons ECM. Why Conferences Matter-An Illustration from the International Marine Conservation Congress. Front Mar Sci. 2017. https://doi.org/10. 3389/fmars.2017.00257.

3. Abelson J, Forest P, Eyles J, Smith P, Martin E, Gauvin F. Deliberations about deliberative methods: issues in the design and evaluation of public participation processes. Soc Sci Med. 2003;57: 239-51.

Publisher's note Springer Nature remains neutral with regard to jurisdictional claims in published maps and institutional affiliations. 